Journal of Biological Sciences 10 (4): 355-361, 2010

ISSN 1727-3048

(C) 2010 Asian Network for Scientific Information

\title{
Population Characterization of Planktonic Shrimp, Acetes japonicus (Decapoda: Sergestidae) using RAPD Technique
}

\author{
${ }^{1}$ D. Aziz, ${ }^{1}$ S.S. Siraj, ${ }^{1,2}$ A. Arshad, ${ }^{2}$ S.M. Nurul Amin and ${ }^{1}$ S.A. Harmin \\ ${ }^{1}$ Department of Aquaculture, Faculty of Agriculture, \\ ${ }^{2}$ Laboratory of Marine Science and Aquaculture, Institute of Bioscience, \\ Universiti Putra Malaysia, 43400 UPM, Serdang, Selangor, Malaysia
}

\begin{abstract}
Genomic DNA of sergestid shrimp, Acetes japonicus was successfully extracted by using the Promega Wizard Genomic DNA Purification Kit. Population genetic characterization of $A$. japonicus along the western coast of Peninsular Malaysia (state of Perak, Malacca and Kedah) was examined using the Random Amplified Polymorphic DNA (RAPD) marker. Twenty oligonucleotides from operon A kit were used to screen the populations, of which 6 were able to be amplified (OPA03, OPA04, OPA07, OPA09, OPA10, OPA16). The percentages of polymorphic bands of the three populations investigated varied from 57.77 to $87.77 \%$. Genetic distances between populations and cluster analysis from UPGMA grouped the populations into two major clusters. The Perak and Malacca populations were in one cluster, while the Kedah population was clustered by itself, indicating a different population. The genetic distance was highest as 0.0999 for the Kedah and the Malacca populations while lowest value was 0.0413 for the Perak and the Malacca populations, which probably have a closed ancestral relationship. The results of this study suggested that RAPD analysis, if carried out carefully and accurately would give a good indication of the separation between individuals of different populations and is suitable for identification of closely related genotypes.
\end{abstract}

Key words: Acetes shrimp, population characteristic, Peninsular Malaysia

\section{INTRODUCTION}

Acetes shrimps are small pelagic shrimp living mainly in the estuaries and shallow coastal waters of the tropical and subtropical regions. The Acetes shrimps are an important fisheries commodity in Malaysia and have the potential for large-scale commercial aquaculture (Amin et al., 2007). Acetes affords a major source of protein to some of the people in Asia and East Africa (Omori, 1975). The shrimp is mainly fished with various kinds of push nets set near the shore against the flow of the tide. Only a small proportion of the catch is sold as fresh shrimp, but the greater proportion is dried, salted or fermented with salt in various ways for food. A shrimp paste is manufactured extensively throughout Southeast Asia (Omori, 1975).

Acetes japonicus is distributed along the coasts of the Yellow Sea, South China Sea (Lei, 1988), Gulf of Thailand (Omori, 1975), Java Sea and Straits of Malacca (Pathansali, 1966; Omori, 1975). It has also been reported from both east and west coast of India (Achuthankutty, 1973), Bangladesh (Mahmood et al.,
1978) and Manora channel near Karachi of Pakistan (Tirmizi and Ghani, 1982). In Japan, the species is found in neretic waters around the islands of Kyushu and western part of Honshu (Harada, 1968) and is commercially fished in the Ariake Sea. Great swarms of this species can occur in Suruga Bay usually in July and August (Omori, 1975). The species is also recorded in Viet Nam (Omori, 1975) and along the coast of Pakistan and in Kuwait Bay of the Gulf of Arabia (Enomoto, 1971).

The use of Random Amplification of Polymorphic DNA (RAPD) for population characterization had gained attention among researchers over the past decades. It is a PCR based amplification protocol of random locations of the segments of DNA. This makes RAPD marker one of the popular molecular markers for comparing the DNA of biological systems that have not had the attention of the scientific community, or in a system in which relatively few DNA are being compared. In recent years, RAPD is used to characterize and trace the phylogeny of diverse plant and animal species (Melcher, 1997).

Random Amplified Polymorphic DNA (RAPD) technique is a simple and rapid method for generating

Corresponding Author: Siti Shapor Siraj, Department of Aquaculture, Faculty of Agriculture, Universiti Putra Malaysia, 43400 UPM, Serdang, Selangor, Malaysia 
genetic markers without prior knowledge of the genome being analyzed (Williams et al., 1990). Research on RAPD markers has been improved over the years and extensively being used on penaeid shrimps (Tassanakajon et al., 1998) but none on Acetes. It is imperative to understand the genetic diversity of the Acetes wild stocks for successful broodstock and genetic resource management. Unlike traditional PCR analysis, RAPD does not require any specific knowledge of the DNA sequence of the target organism: the identical 10-mer primers will or will not amplify a segment of DNA, depending on positions that are complementary to the primers' sequence (Melcher, 1997).

So far, there have been no published reports on genetics of Acetes in Malaysia. However, details studies on population biology and reproduction of this genus have been reported by Arshad et al. $(2007 ; 2008)$ and Amin et al. (2008a, b, 2009a, b), suggesting that the catch is unsustainable. Therefore, the present study was undertaken for accessing the genetic relationship within and among three populations of Acetes in Malaysia using RAPD marker technique. RAPD technique was used as a tool in the population genetics of the Acetes japonicus shrimp to provide information on their genetic stock structure and indicates the population differentiation between the Acetes japonicus from the three main fishery regions of Peninsular Malaysia.

\section{MATERIALS AND METHODS}

Sampling: The samples were collected from three different locations (Kuala Sala, Kedah; Kuala Gula, Perak and Klebang Besar, Malacca) between March 2007 and February 2008 along the west coast of Peninsular Malaysia (Fig. 1). The samples were obtained from the fishermen directly after the harvesting of the shrimps. Fresh Acetes samples were kept cool in an ice container and transported to the laboratory. In the laboratory, the samples were stored in the freezer at $-70^{\circ} \mathrm{C}$ to maintain its quality.

Sample identification: The specimens of Acetes joponicus were sorted in the laboratory using a Nikon dissecting microscope (Nikon-122764, Japan). Sex was determined by the presence or absence of petasma on the first pleopods and clasping spine on the lower antennular flagellum (Omori, 1975). The study of Omori (1975) and Zafar (2000) were followed during taxonomic identification of the Acetes japonicus.

DNA extraction: The procedure of DNA extraction was adapted from Mor and Mayer (1996) and Crossland et al.

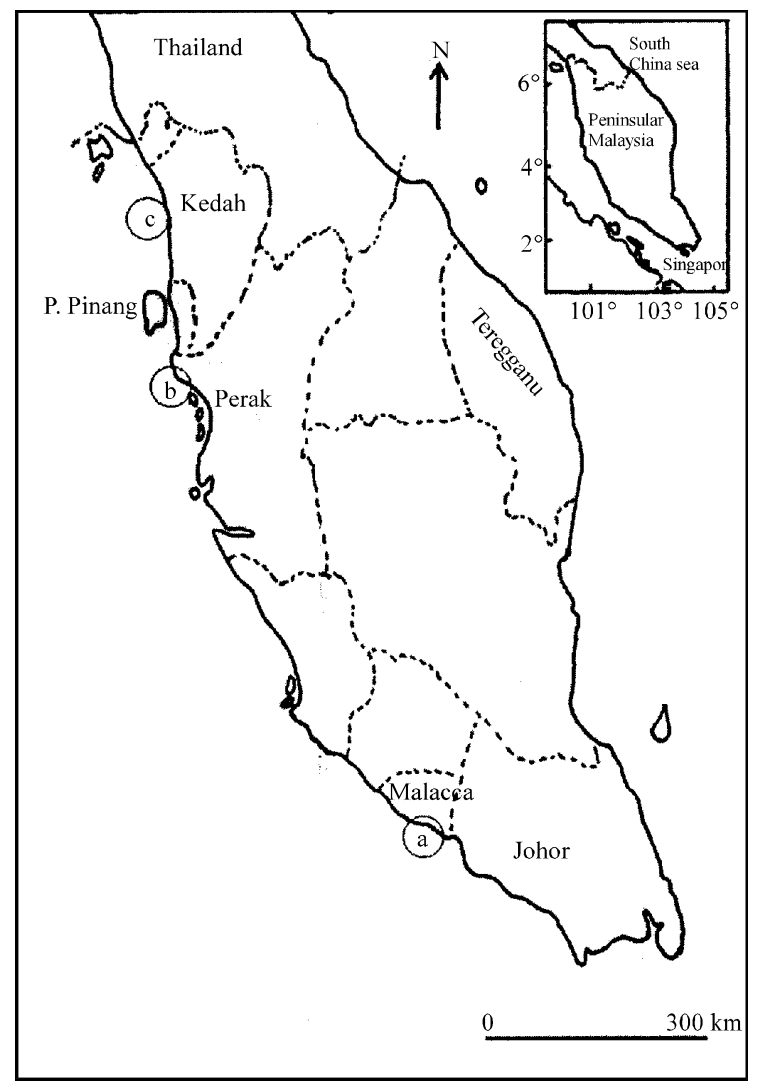

Fig. 1: Geographical location of the sampling sites in the Peninsular Malaysia. a, Klebang Besar, Malacca; b, Kuala Gula, Perak; c, Kuala Sala, Kedah

(1993). DNA used in the study was extracted from a total 90 samples of Acetes japonicus, comprised of 30 (15 males and 15 females) from Kedah, 30 ( 15 males and 15 females) from Perak and 30 ( 15 male and 15 females) from Malacca. DNA samples extracted from the whole organisms using the Wizard Genomic DNA Purification Kit developed by Promega. A minimum sample of $0.02 \mathrm{~g}$ was placed into each microtubes. The three main steps involved in the preparation of the tissues were lysis and protein precipitation, DNA precipitation and DNA rehydration.

PCR amplification: A total of twenty 10-mer random primers developed from First BASE Laboratories Sdn Bhd, Malaysia were tested (Table 1). The standard PCR amplification was performed in the MJ Research Peltier Thermal Cycler(PTC-200) with $10 \mu \mathrm{L}$ total reaction mixture volume consisting of genomic DNA, $10 \mathrm{X}$ PCR buffer, $250 \mu \mathrm{M}$ of each dNTPs, 50 pmole of primer, 1.5 units of Taq polymerase, $2.0 \mathrm{mM}$ of $\mathrm{MgCl}_{2}$ and deionised distilled water top up to $10 \mu \mathrm{L}$. A drop of mineral oil was added to 
overlay the PCR mixture. PCR tubes was placed in the thermal cycler which were programmed at $3 \mathrm{~min}$ for predenaturation at $95^{\circ} \mathrm{C}$, denaturation at $94^{\circ} \mathrm{C}$ for $30 \mathrm{sec}$, primer annealing at $32^{\circ} \mathrm{C}$ for $30 \mathrm{sec}$ and primer extension at $72^{\circ} \mathrm{C}$ for $35 \mathrm{sec}$. This profile was performed 39 times and then the products was completed by a single extension for $5 \mathrm{~min}$ at $72^{\circ} \mathrm{C}$ for only the last cycle and the temperature was held at $4^{\circ} \mathrm{C}$. The amplification products were then electrophoretically analyzed in $2.0 \%$ agarose gels in 1x TBE buffer and visualized under UV light after ethidium bromide staining (Maniatis et al., 1982). The $100 \mathrm{bp}$ DNA step ladder was used as the molecular weight standard.

Data analysis: All reproducible and resolvable bands ranging from 200 to $1500 \mathrm{bp}$ were scored from the gel. The presence (1) and absence ( 0 ) of an amplified fragment was scored without further consideration of the quantitative aspect of the results (i.e., band intensity differences between homo and heterozygotes). The scores obtained using all primers in the RAPD analysis were then pooled for constructing a single data matrix. This data matrix was used for estimating polymorphic loci, genetic distance and constructing an unweighted pair group method of arithmetic mean (UPGMA) dendrogram among populations using the POPGENE (version 1.32) (Yeh et al., 1999) computer program. The similarity index values (SI) between the RAPD profiles were calculated from the RAPD markers according to the following formula:

$$
\text { Similarity index }(\mathrm{SI})=2 \mathrm{~N}_{\mathrm{AB}} /(\mathrm{NA}+\mathrm{NB})
$$

where, $\mathrm{N}_{\mathrm{AB}}$ is the total number of RAPD bands shared by individuals $A$ and $B$ and $\mathrm{N}_{A}$ and $N_{B}$ are the number of

\begin{tabular}{llcc} 
Table 1: A list of RAPD primers used in this population study \\
\hline & & & $\begin{array}{c}\text { Primers used in } \\
\text { populations study }\end{array}$ \\
Primers & Primers sequences 5' to 3' & Primers tested & - \\
OPA01 & CAGGCCCTTC & $\checkmark$ & - \\
OPA02 & TGCCGAGCTG & $\checkmark$ & \\
OPA03 & AGTCAGCCAC & $\checkmark$ & - \\
OPA04 & AATCGGGCTG & $\checkmark$ & - \\
OPA05 & AGGGGTCTTG & $\checkmark$ & \\
OPA06 & GGTCCCTGAC & $\checkmark$ & - \\
OPA07 & GAAACGGGTG & $\checkmark$ & \\
OPA08 & GTGACGTAGG & $\checkmark$ & - \\
OPA09 & GGGTAACGCC & $\checkmark$ & - \\
OPA10 & GTGATCGCAG & $\checkmark$ & - \\
OPA11 & CAATCGCCGT & $\checkmark$ & - \\
OPA12 & TCGGCGATAG & $\checkmark$ & - \\
OPA13 & CAGCACCCAC & $\checkmark$ & \\
OPA14 & TCTGTGCTGG & $\checkmark$ & - \\
OPA15 & TTCCGAACCC & $\checkmark$ & - \\
OPA16 & AGCCAGCGAA & $\checkmark$ & - \\
OPA17 & GACCGCTTGT & $\checkmark$ & - \\
OPA18 & AGGTGACCGT & $\checkmark$ & \\
OPA19 & CAAACGTCGG & $\checkmark$ & \\
OPA20 & GTTGCGATCC & $\checkmark$ & \\
\hline & & & \\
\hline
\end{tabular}

fragments scored for each individual, respectively (Lynch, 1991). Between population similarity $\left[\mathrm{S}_{\mathrm{ij}}\right]$ was calculated as the average similarity between randomly paired individuals from populations $i$ and $j$ (Lynch, 1991).

\section{RESULTS}

Screening and optimization of RAPD primers: A total of 20 primers were tested for the Acetes DNA and were screened for a single individual, but only 6 primers (Table 1) were used (OPA03, OPA04, OPA07, OPA09, OPA10 and OPA16). These six primers worked well with all the samples and were used in this RAPD analysis. Figure 2 and 3 represent the RAPD profiles generated by the primer used to variety of samples from the selected locations.

Polymorphic bands: The six primers yielded a total of 402 distinct polymorphic bands (either occurring in or absent in $<95 \%$ of all individuals) and therefore used in this analysis. Among the six primers, OPA10 and OPA16 resulted in the highest number of polymorphic bands and thus a high level of polymorphism (Table 2). The percentage for the total number of polymorphic band for OPA 10 was $87.77 \%$ and OPA1 6 was $78.88 \%$, while the size range for OPA10 was from 300 to $1500 \mathrm{bp}$ and for OPA16 from 200 to $1500 \mathrm{bp}$.

Similarity indices amongst the population: The average genetic identity within populations (S) across all the primers ranged from 0.7550 to 0.7556 (Table 3 ). The highest similarity index within a population was found in Acetes japonicus from Malacca (0.7556), whereas slightly lower similarity indices were observed in Kedah and Perak at 0.7554 and 0.7550 , respectively.

Table 2: Number of bands and the size range of the RAPD fragments in primers RAPD kit A of Acetes joponicus

\begin{tabular}{llllc}
\multicolumn{5}{c}{ primers RAPD kit A of Acetes japonicus } \\
\hline & & $\begin{array}{l}\text { Size range } \\
\text { Primer }\end{array}$ & $\begin{array}{l}\text { No. of } \\
\text { Amplified bands }\end{array}$ & $\begin{array}{l}\text { Polymorphic } \\
\text { frament } \\
\text { amplified (\%) }\end{array}$ \\
\hline OPA03 & AGTCAGCCAC & $200-1500$ & 64 & 71.11 \\
OPA04 & AATCGGGCTG & $300-1500$ & 52 & 57.77 \\
OPA07 & GAAACGGGTG & $200-1500$ & 66 & 73.33 \\
OPA09 & GGGTAACGCC & $400-1500$ & 70 & 77.77 \\
OPA10 & GTGATCGCAG & $300-1500$ & 79 & 87.77 \\
OPA16 & AGCCAGCGAA & $200-1500$ & 71 & 78.88 \\
\hline
\end{tabular}

Table 3: Total number of bands, percentages of polymorphic bands and similarity estimates within populations (average for all primers) observed in 3 populations of Acetes joponicus

\begin{tabular}{lcccc}
\hline $\begin{array}{l}\text { Sample } \\
\text { site }\end{array}$ & $\begin{array}{l}\text { Total bands } \\
\text { observed }(\mathrm{N})\end{array}$ & $\begin{array}{l}\text { Polymorphic } \\
\text { bands }(\mathrm{N})\end{array}$ & $\begin{array}{l}\text { Polymorphic } \\
\text { bands (\%) }\end{array}$ & $\begin{array}{l}\text { Similarity index } \\
\text { within populations } \\
\text { S+SD) }\end{array}$ \\
\hline Kedah & 60 & 50 & 83.33 & $0.7554 \pm 0.0245$ \\
Perak & 60 & 55 & 91.67 & $0.7550 \pm 0.0236$ \\
Melaka & 60 & 46 & 76.67 & $0.7556 \pm 0.0229$ \\
\hline
\end{tabular}




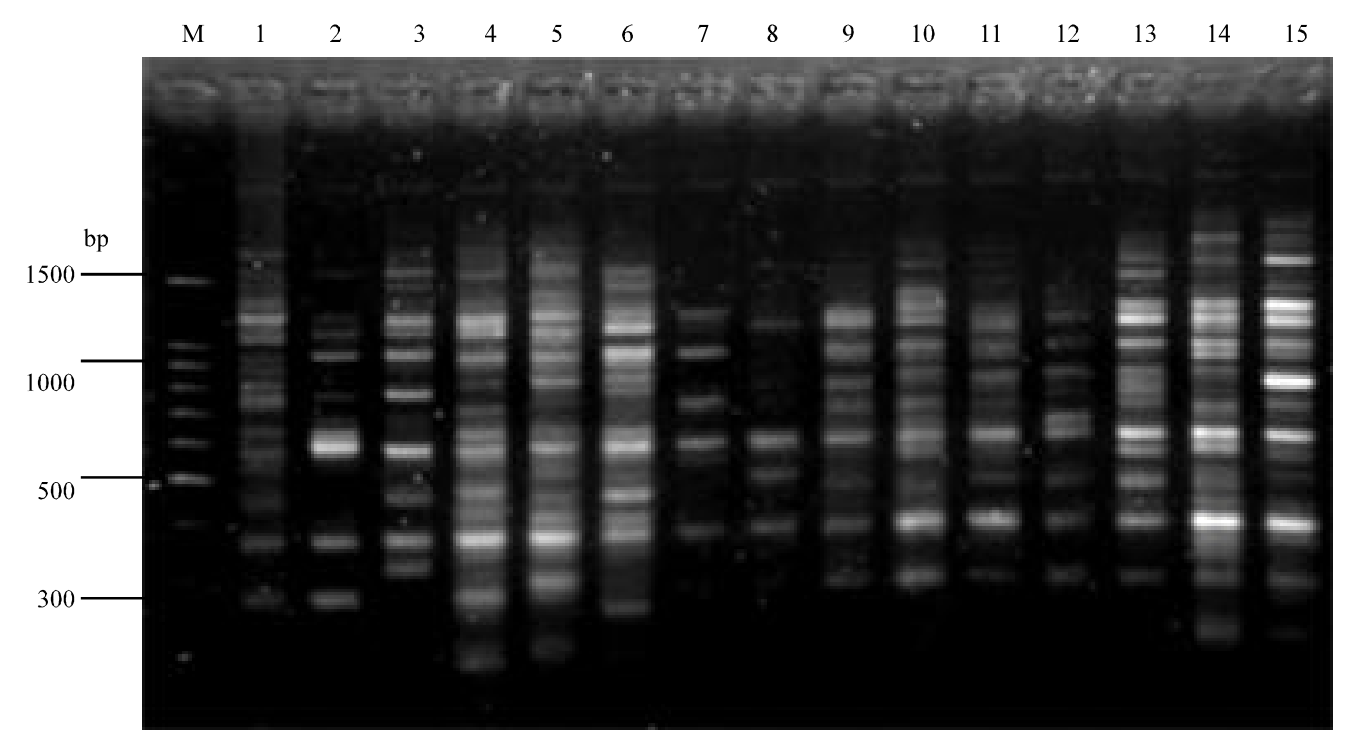

Fig. 2: RAPD profile (lane 1 to 15) of female Acetes japonicus samples with the primer OPA10 from Malacca population. Lane $\mathrm{M}$ is 100 bp ladder

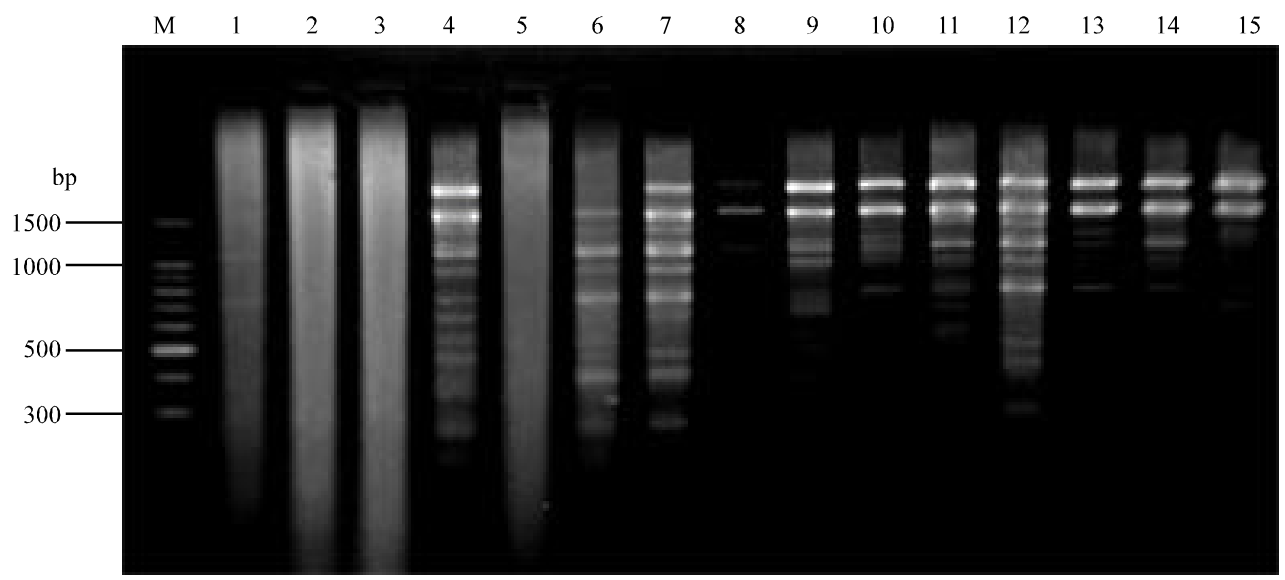

Fig. 3: RAPD profile (lane 1 to 15) of male Acetes japonicus samples with the primer OPA16 from Perak population. Lane $\mathrm{M}$ is 100 bp ladder

Similarity index within and between populations: The average genetic similarity between populations across all the primers ranged from 0.9049 to 0.9595 . Interpopulation SI $\left[\mathrm{S}_{\mathrm{ij}}\right.$ ] for the Perak population versus the Malacca population was higher (0.9595) than those for between-population comparisons (Perak-Kedah: 0.9259; Malacca-Kedah: 0.9049). The Perak population was closer to the Kedah population with a genetic similarity of 0.9259 in comparison to the genetic similarity between the Malacca and Kedah populations which was slightly lower and seem to be reproductively isolated.

Genetic distance and dendrogram: The genetic distance values were converted from a measure of
Table 4: Genetic distances and similarities between populations based on 6

\begin{tabular}{|c|c|c|c|}
\hline Pop ID & Perak & Malacca & Kedah \\
\hline Perak & & 0.9595 & 0.9259 \\
\hline Malacca & 0.0413 & & 0.9049 \\
\hline Kedah & 0.0770 & 0.0999 & \\
\hline
\end{tabular}

between-population similarity corrected by the withinpopulation values based on Nei and Li's (1979) as shown in Table 4. These values were then subjected to phylogenetic reconstruction. The UPGMA dendrogram resulted from the overall primers indicated three population groups which composed of population 1 from Perak, population 2 of Malacca and population 3 belonging to Kedah (Fig. 4). The Malacca and Kedah 


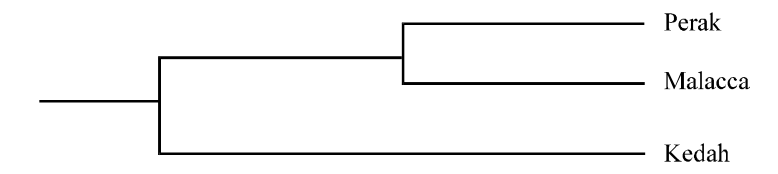

$\begin{array}{rrrrrr}0.100 & 0.080 & 0.060 & 0.040 & 0.020 & 0.000\end{array}$

Fig. 4: UPGMA dendrogram based on Nei and Li (1979) genetic distance, summarizing data on differentiation between $A$. japonicus populations according to random amplified polymorphic DNA (RAPD) analysis

populations had the greatest genetic distance of 0.0999 whereas the genetic distance for the Perak and the Kedah populations was lower with the value of 0.0770 . The genetic distance for the Perak and the Malacca populations however, was the lowest with the value of 0.0413 , which means that the pair has a close ancestral relationship between them. The dendrogram indicated the segregation of three populations into two clusters: the Perak and the Malacca populations in one cluster whilst the Kedah population is a group by itself.

\section{DISCUSSION}

Acetes fisheries operate mainly in Asia and to a much lesser extent in Africa and South America (Omori, 1975). $A$. chinensis, $A$. erythraeus, $A$. indicus, $A$. japonicus, $A$. serrulatus, $A$. sibogae and $A$. vulgaris form single or in combination, commercial fisheries in Bangladesh, China, India, Indonesia, Japan, Korea, Malaysia, Pakistan, Philippines, Singapore and Thailand (Omori, 1975; Zafar, 2000). Fishing grounds are usually located in calm, muddy, near intertidal zones, where waters are shallower than $5 \mathrm{~m}$ (Omori, 1975). In the coastal waters of Malacca, Peninsular Malaysia, fishermen catch Acetes 3-5 days during the neap tide between the new moon and full moon (Amin et al., 2008a). There are several accounts of the Acetes fishery from west Malaysia or Malay Peninsula (Amin et al., 2008a; Pathansali, 1966; Omori, 1975; Johnson, 1976). The annual landing of Acetes for the period of 2004 was 7,528 tons in Malaysia (DOF, 2004). It is thought that the catch from the west coast comprises $85 \%$ or more of the total Acetes catch in Peninsular Malaysia (Omori, 1975).

Random Amplified Polymorphic DNA is a very sensitive technique. Hence, all the PCR parameters that may influence the banding patterns should be optimized carefully. In order to get reliable banding profiles in this study, the DNA extraction protocol was followed strictly. The ratio between the DNA and the primer concentration, the amount of Taq polymerase, $\mathrm{MgCl}_{2}$ concentration and dNTPs concentration had been adjusted and optimized in this pilot study. After optimizations were done, the PCR condition was followed strictly for every subsequent reaction. The RAPD-PCR method can be applied by single-primer DNA amplification (Mulcahy et al., 1993, 1995 ) but it is used best for genetic differences within the populations. In this study, different primers were used because it is better to detect the genetic diversity and similarity in organisms between the populations (Levin et al., 1993; Bernardi and Talley, 2000).

The six primers that were selected were common in all the populations which mean that the bands were scoreable, reproducible and contain polymorphic banding patterns in all the three populations. The band-sharing approach based on the presence or absence of amplified DNA fragments was used to estimate similarity indices. The mean estimated similarity within each population was high, reflecting a high similarity of compared sequences. The A. japonicus of Malacca showed the highest level of within-population similarity, whereas the remaining populations showed similar levels.

The genetic distance was converted from a measure of between-population similarity corrected by the withinpopulation values (Lynch, 1991). The genetic distance between the Malacca and the Kedah populations was the highest meaning it was not ancestrally close compared to the other populations, while the genetic distance between the Perak and the Kedah populations was lower, however it was still not as close as the Perak and the Malacca populations which has the lowest genetic distance between them. The ancestral relationship was the closest in the Perak and the Malacca populations. The UPGMA dendrogram indicated a shared ancestral relationship among Perak and Malacca whereas Kedah showed a greater genetic distance from the rest of the population.

The cluster analysis based on RAPD markers grouped all the populations into two major groups. The Perak and Malacca populations were clustered in one group while the Kedah populations were clustered by itself (Fig. 4). Geographic heterogeneity analysis illustrated highly significant differences in genotype frequencies among the group 1 which are Perak and Malacca and group 2 which is Kedah. This indirectly indicates that the $A$. japonicus from Kedah should be regarded as a different stock.

The genetic break observed in the dendrogram could be explained by the limitation of gene flow caused by the surface currents of the Strait of Malacca, which serves as an overflow channel during both Northeast and Southwest monsoons that splits the populations into two clusters. The shrimps from the Kedah population could be 
from the Thailand stock coming from Andaman Sea. It would be useful to examine the genetic differentiation further south along the coast and perhaps include samples from the sites from the Penang and the Selangor state to clarify this contradiction.

Another possible reason for the genetic break could be that the population being analyzed was disturbed and might not be typical for the area. Accordingly, the unexpected relationships among geographically different A. japonicus need to be clarified by a larger number of RAPD primers. The degree of taxonomic resolution of the technique could be improved by testing more primers i.e., Operon Kit B and C. Moreover, to obtain more reliable results, a larger number of samples and increased population sizes may also be required.

Research on the population genetic structure of the jumbo squid (Dosidicus gigas) using the RAPD analysis (Sandoval-Castellanos et al., 2007) also gave the same result of a genetic break. Some authors pointed that physical, biological and oceanographic factors like temperature, high productivity zones, availability of food and oceanic currents (Anderson and Rodhouse, 2001) could influence the migration and thus the reproductive interchange between populations making the dynamics of the genetic differentiation slightly complex. The temporal variation in the squid which was moderate and not significant, could be explained by stochastic processes, genetic drift, or sampling error.

Application of RAPD in the small aquatic organism like Acetes shrimps are necessary and also is reliable because RAPD markers are expected to offer a good representation of genomic diversity. This is probably because of their random amplification and their ability to represent any region of the nuclear genome. The six RAPD primers were able to amplify and produced polymorphic loci to the present population. The Perak and the Malacca populations were probably derived from closely related ancestors as the genetic distance shown was low between them. Whilst, the genetic distance between Malacca and the Kedah populations was greatest among the other populations because they probably belong to different stocks.

This is the first study done using RAPD technique on Acetes shrimps which could provide basic information for optimizing identification of stocks, stock enhancement, breeding programs, management for sustainable yield and preservation of genetic diversity. Further study using more populations, greater sample size and more markers (Microsatellites, Single Nucleotide Polymorphism, Amplified Fragment Length Polymorphism) are required in order to assemble a complete picture about the population structure of the Acetes japonicus along the west coast of Peninsular Malaysia.

\section{ACKNOWLEDGMENTS}

This research is part of a Ph.D thesis. The authors would like to thank the Ministry of Science, Technology and Innovation (MOSTI), Malaysia, for the research grant (05-01-04-SF0613), the staffs of Department of Aquaculture, Faculty of Agriculture, UPM for the technical support and laboratory facilities provided and staffs of Department of Biology, Faculty of Science, UPM for their valuable suggestions and co-operation.

\section{REFERENCES}

Achuthankutty, C.T., 1973. Sexual abnormalities in the genus Acetes (Sergestidae, Decapoda). Curr. Sci., 42: 827-828.

Amin, S.M.N., A. Arshad, S.S. Siraj and S.B. Japar, 2007. The biology and life history of sergestid shrimp Acetes indicus (Decapoda: Sergestidae) in the coastal waters of Malacca, Peninsular Malaysia. Bioscientist, 5: 9-17.

Amin, S.M.N., A. Arshad, B. Japar Sidik and S.S. Siraj, 2008a. Growth, mortality and yield-per-recruit of sergestid shrimp, Acetes intermedius Omori, 1975 (Decapoda: Sergestidae) from length frequency analysis in the coastal waters of Malacca, Peninsular Malaysia. Pertanika J. Trop. Agric. Sci. 31: 95-106.

Amin, S.M.N., A. Arshad, S.B. Shamsudin, S.B. Japar and S.S. Siraj, 2008b. Catch per unit effort of estuarine push net with emphasis on occurrence and abundance of Acetes shrimps in the coastal waters of Malacca, Peninsular Malaysia. Pertanika J. Sci. Tech., 16: 281-289.

Amin, S.M.N., A. Arshad, S.B. Japar and S.S. Siraj, 2009a. Age structure, mortality and yield-per-recruit of sergestid shrimp, Acetes indicus (Decapoda: Sergestidae) from the coastal waters of Malacca, Peninsular Malaysia. J. Applied Sci., 9: 801-814.

Amin, S.M.N., A. Arshad, S.S. Siraj and S.B. Japar, $2009 \mathrm{~b}$. Population structure, growth, mortality and yield per recruit of segestid shrimp, Acetes japonicus (Decapoda: Sergestidae) from the coastal waters of Malacca, Peninsular Malaysia. Indian J. Mar. Sci., 38: 57-68.

Anderson, C. I. H. and P.G. Rodhouse, 2001. Life cycles, oceanography and variability: ommastrephid squid in variable environments. Fish. Res., 54: 133-143.

Arshad, A., S.M. Nurul Amin, G.T. Yu, S.Y. Oh, J.S. Bujang and M.A. Ghaffar, 2008. Population characteristics, length-weight and length-length relationships of Acetes vulgaris (Decapoda: Sergestidae) in the coastal waters of Pontian, Johor, Peninsular Malaysia. J. Biol. Sci., 8: 1298-1303. 
Arshad, A., S.M.N. Amin, S.S. Siraj and S.B. Japar, 2007. New distribution records of sergestid shrimp, Acetes intermedius (Decapoda: Sergestidae) from Peninsular Malaysia with notes on its population characteristics. J. Biol. Sci., 7: 1305-1313.

Bernardi, G. and D. Talley, 2000. Genetic evidence for limited dispersal in the coastal California killifish, Fundulus parvipinnis. J. Exp. Mar. Bio. Ecol., 255: 187-199.

Crossland, S., D. Coates, J. Grahame and P.J. Mill, 1993. Use of random amplified polymorphic DNAs (RAPDs) in separating two sibling species of Littorina. Ecol. Prog. Ser., 96: 301-305.

DOF (Department of Fisheries), 2004. Year Book of Fishery Statistics. Department of Fisheries, Malaysia.

Enomoto, Y., 1971. Oceanography and biological study of shrimps in the waters adjacent to the eastern coasts of the state of Kuwait. Bull. Tokai Reg. Fish. Res. Lab., 66: 1-74.

Harada, E., 1968. Ecology and biological production of Lake Naka-umi and adjacent regions: Seasonal changes in distribution and abundance of some decapod crustaceans. Spec. Publ. Set Mar. Biol. Lab., 2: 75-103.

Johnson, D.S., 1976. Prawns of the Malacca straits and Singapore waters. J. Mar. Biol. Assoc. Ind., 18: 1-54.

Lei, M., 1988. Studies in the biology of Acetes japonicusi Kishinouye in the Eastern Coastal Waters of Guangdong Province, China. 1st Edn., Ocean Press, Bejing, pp: 234-243.

Levin, I., L.B. Crittenden and J.B. Dodgson, 1993. Genetic map of the chicken $\mathrm{Z}$ chromosome using random amplified polymorphic DNA (RAPD) markers. Genomics, 16: 224-230.

Lynch, M., 1991. Analysis Population Genetic Structure by DNA Fingerprinting. In: DNA Fingerprinting: Approaches and Applications, Burke, T., G. Dolf, A.J. Jeffreys and R. Wolff (Eds.). Birkhäuser Verlag, Basel, Switzerland, pp: 113-126.

Mahmood, N., Y.S.A. Khan and M. Hussain, 1978. Shrimp fishery: Records of three sergestid shrimps in Bangladesh. Proceedings of the Zoological Society of Bangladesh (ZSB'78), Zoological Society, Dhaka, Bangladesh, pp: 204-214.

Maniatis, T., E.F. Fritsch and J. Sambrock, 1982. Molecular Cloning: A Laboratory Manual. 3rd Edn., Cold Spring Harbor Laboratory, Cold Spring Harbor, New York.

Melcher, U., 1997. Molecular Genetics. Cold Spring Habor Laboratory Press, New York, pp: 127.
Mor, H. and G.C. Mayer, 1996. Diversity among isolates of Verticillium lecanii as expressed by DNA polymorphism and virulence towards Bemisia tabaci. Phytoparasitica, 24: 111-118.

Mulcahy, D.L., M. Cresti, H.F. Linskens, C. Intrieri, O. Silverstoni, R. Vignani and M. Pancaldi, 1995. DNA fingerprinting of Italian grape varieties: A test of reliability in RAPDs. Adv. Hort. Sci., 9: 185-187.

Mulcahy, D.L., M. Cresti, S. Sansavini, G.C. Douglas, H.F. Linskens, G. Bergamini, R. Vignani and M. Pancaldi, 1993. The use of random amplified polymorphic DNA to fingerprint apple genotypes. Sci. Hort., 54: 89-96.

Nei, M. and W.H. Li, 1979. Mathematical model for studying genetic variation in terms of restriction endonucleases. Proc. Natl. Acad. Sci. USA., 76: 5269-5273.

Omori, M., 1975. The systematics, biogeography and fishery of epipelagic shrimp shrimps of the genus Acetes (Crustacea, Decapoda, Sergestidae). Bull. Ocean Res. Inst. Uni. Tokyo, 7: 1-91.

Pathansali, D., 1966. Acetes (Sergestidae) from the Malay Peninsula. Bull. Nat. Muse. Sing., 33: 59-63.

Sandoval-Castellanos, E., M. Uribe-Alcocer and P. Diaz-Jaimes, 2007. Population genetic structure of jumbo squid (Dosidicus gigas) evaluated by RAPD analysis. Fish. Res., 83: 113-118.

Tassanakajon, A, S. Pongsomboon, P. Jarayabhand, S. Klinbunga and V. Boonsaeng, 1998. Genetic structure in wild populations of black tiger shrimp (Penaeus monodon) using randomly amplified polymorphic DNA analysis. J. Mar. Biotech., 6: 249-254.

Tirmizi, N.M. and N.A. Ghani, 1982. New distributional records for three species of Acetes (Decapoda, Sergistidae). Crustaceana, 42: 44-53.

Williams, J.G.K., A.R. Kubelik, K.J. Livak, J.A. Rafalski and S.V. Tingey, 1990. DNA polymorphisms amplified by arbitrary primers are useful as genetic markers. Nucleic Acids Res., 18: 6531-6535.

Yeh, F.C., R.C. Yang and T. Boyle, 1999. POPGENE Version 1.32: Microsoft Window-based Freeware for Population Genetic Analysis. University of Alberta, Edmonton.

Zafar, M., 2000. Study on Sergestid shrimp Acetes in the vicinity of Mathamuhuri river confluence, Bangladesh. Ph.D. Thesis, University of Chittagong, pp: 223. 